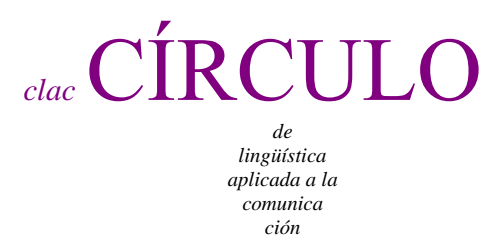

$45 / 2011$

\title{
APUNTES SOBRE FRASEOLOGÍA HISTÓRICA: LAS EXPRESIONES FIGURADAS CON VERBOS DE MOVIMIENTO EN ESPAÑOL MEDIEVAL
}

\author{
Ana Serradilla Castaño \\ Universidad Autónoma de Madrid \\ ana serradilla en uam es
}

Resumen

Los estudios de fras eología son cada vez m ás frecuentes, sobre todo en una dimensión sincrónica y contrastiva; en la actualida d, está surgiendo tam bién un interés por el estudio de las locuciones desde una perspectiva diacrónica y es en esta línea en la que se enmarca el presente trabajo. Este artículo pretende dar cuenta de las frases hechas (expresiones con sentido figurado) con verbos de movimiento tales como abrir, cerrar, subir, bajar, caer, ir, salir, entrar, andar, echar, llevar, sacar, meter, venir o volver documentadas en español medieval.

Locuciones como abrir los ojos, cerrar la puerta, caer en el lazo, ir por lana y venir trasquilado, salir de seso, entrar de rondón, andar de puerta en puerta, echar suertes, venir a las manos, llevar al cabo, meter manos, sacar de pila o volver la hoja

Serradilla Castaño, Ana. 2011.

Apuntes sobre fraseología histórica:

las expresiones figuradas con verbos de movimiento en español medieval.

Círculo de Lingüística Aplicada a la Comunicación 45, 21-54.

http://www.ucm.es/info/circulo/no45/serradilla.pdf

DOI 10.5209/rev CLAC.2011.v45.2

(C) 2011 Ana Serradilla Castaño. Círculo de Lingüística Aplicada a la Comunicación (clac) Universidad Complutense de Madrid. ISSN 1576-4737. http://www.ucm.es/info/circulo 
aparecen frecuentemente en los textos medievales con un significado figurado que no es deducible de la sum a de los significados de los elem entos que la s integran. En este estudio se analiza el dif erente grado de pr oductividad de estos verbos para entrar a formar parte de estas expresiones; se obser va la capacidad de los verbos seleccionados para extenderse metafóricamente; se analiza la e xistencia de metáforas universales, se presta atención a los casos de variación fraseológica y se atiende a los primeros casos de desautomatización.

Palabras clave : unidad fraseológica, verbo de movimiento, $\mathrm{m}$ etáfora, variación fraseológica.

\section{Abstract}

Phraseology studies are increasingly frequent, especially in a synchronic and contrastive dimension; interest in the study of phrases from a diachronic point of view is now rising and the pr esent work is $f$ ocused on this a spect. This a rticle tries to c ompile some of those set ph rases (ph rases with a figurative sense) with verbs of movem ent such as abrir, cerrar, subir, bajar, caer, ir, salir, entrar, andar, echar, llevar, sacar, meter, venir or volver, phrases documented in medieval Spanish.

Expressions such as abrir los ojos, cerrar la puerta, caer en el lazo, ir por lana y venir trasquilado, salir de seso, entrar de rondón, andar de puerta en puerta, echar suertes, venir a las manos, llevar al cabo, meter manos, sacar de pila or volver la hoja appear frequently in the medieval texts with a figurative m eaning that is not deductible from the sum of the $m$ eanings of the elem ents that form them. In this study we aim to analyze the different degree of productivity of these verbs when trying to be a part of these expre ssions; the capac ity of the se lected corpus of verbs seem s to spread metaphorically; we will also analyze the existence of uni versal metaphors while paying attention to the cases of variation in phrases and studying the first cases of deautomatization.

Key words: phraseological unit, verb of movement, metaphor, phraseological variation. 
Índice

1. Introducción 24

2. Usos literales y usos figurados. Corpus de locuciones. 26

3. Análisis de la documentación medieval 31

3.1. abrir 31

3.2. cerrar 32

3.3. caer 33

3.4. ir 34

3.5. salir 37

3.6. venir 38

3.7. andar 39

3.8. echar 40

3.9. llevar 42

3.10. Meter 43

3.11. sacar 44

3.12. volver 44

3.13. entrar 46

4. Reflexiones finales 46

Apéndice 49

Bibliografía 50 


\section{Introducción}

Los estudios sobre fraseología son cada vez m ás frecuentes, sobre todo desde una perspectiva sincrónica y contrastiva ${ }^{1}$. Hay que destacar, sin em bargo, que en la actualidad, está surgiendo también un interés por el estudio de las locuciones desde una perspectiva diacrónica ${ }^{2}$ [véanse Form ent (1999), Echenique (2003), Echenique y Martínez Alcalde (2003), Velando Casanova (2 003) o Serradilla Castaño (2006)] y es en esta línea en la que se enmarca el presente trabajo.

En la última década ha habido asim ismo bastante interés por la form a en la que los diccionarios recogen las un idades fraseo lógicas. Se trata de es tudios de corte eminentemente lexicográfico, que nos perm iten conocer cómo eran interpretadas estas expresiones en diferentes m omentos de nuestra historia lingüística. Entre estos trabajos merece la pena destacar los de Martínez Montoro (2001), Martínez Alcalde (2002 ), Acero Durántez (2004) o Martín ez Egido y Ru iz Gurillo (2 006). El estudio que aquí presento no entra estrictam ente, sin e mbargo, en esta categoría de trabajo, ya que, aunque he tenido en cuenta las definiciones lexicográficas, mi interés se centra en el uso de estas expresiones no tanto en los diccionarios como en los propios textos medievales. Así, este artículo pretende dar cuenta de algunas unidades fraseológicas (locuciones con sentido figurado) con verbos de movimiento tales como abrir, cerrar, subir, bajar, caer, ir, salir, entrar, andar, echar, llevar, sacar, meter, venir o volver, documentadas en español medieval.

\footnotetext{
${ }^{1}$ Este trabajo ha sido llevado a cabo en el marco del Proyecto de Investigación Diccionario electrónico multilingüe de verbos amplios de movimiento (andar, ir, venir y volver) (FFI2009-12191), dirigido por Elena de Miguel. También ha sido parcialmente financiado por el Proyecto dirigido por Inés Fernández Ordóñez: Variación y cambio en la sintaxis del español peninsular (FFI2009-10817). U na versión preliminar de est e est udio se prese ntó e n e 1 XXVI Congreso Internacional de Lingüística y Filología Románica. Se tratab a de una v ersión reducid a qu e llev aba co mo títu lo «Un idades fraseológicas co $n$ verbos de movimiento en español medieval».

${ }^{2}$ Un a bibliografía detallada sobre trabajos recientes en fra seología desde dife rentes perspectivas puede consultarse en García Page (2008) o en Robles y Sabater (2007). Desde la diacronía cabe destacar, aparte de las obras a rriba citadas, el curs o de doctorado sobre fraseología hi stórica impartido por $\mathrm{M}^{\mathrm{a}}$ Te resa Echenique en la Universidad de Valencia.
} 
Expresiones $\quad$ como abrir los ojos, cerrar la puerta, caer en el lazo, ir por lana y venir trasquilado, ir a la mano, salir de seso, entrar de rondón, andar de puerta en puerta, andar de boca en boca, echar suertes, venir a las manos, llevar al cabo, meter manos, sacar de pila o volver la hoja aparecen frecuentemente en los textos medievales con un significado figurado que no es deducible de la sum a de los significados de los elementos que las integ ran, característica esta definitoria de las unidades fraseológicas , junto a la p luriverbalidad, la instituc ionalización, la idiomaticidad, la alta frecuencia de uso, la fijación o la variación potencial (Corpas, 1996; Montoro del Arco, 2006...). En este estudio se analiza el diferen te grado de productividad de estos verbos para entrar a formar parte de es tas expresiones: así, co mo verem os a continuación a través de los ejemplos mostrados, m ientras que verbos com o ir; venir o caer tienen una importante presencia en estas construcciones; otros como bajar o subir no entran en estructuras con uso figurado hasta una época posterior. Todos los verbos seleccionado s, pues, unos en mayor medida que otros, tienen capacidad para extenderse metafóricamente y participar en estas expresiones que, en $\mathrm{m}$ uchos casos, responden a la existencia de $\mathrm{m}$ etáforas universales y tienen su orig en en el $\mathrm{m}$ undo grecolatino. Como señala, entre otros, Ángelova Nénkova (2008: 26): “La m etáfora puede reconocerse como uno de los mecanismos de la len gua para ampliar el lexicón”. En la m ayoría de los casos analizados, y lo $\mathrm{m}$ ismo ocurre en otra $\mathrm{s}$ lenguas, la $\mathrm{m}$ etáfora está presente: volver la hoja, meter la mano en el fuego, echar el sello, caer en la red, abrir puerta, salir a plaza... Asimismo, junto a la $\mathrm{m}$ etáfora, la len gua recu rre a otros $\mathrm{m}$ ecanismos $\mathrm{m}$ enos estudiados com o la metonim ia que tam bién contribuyen a la creación de unidades fraseológicas (volver la espalda, volver el rostro, sacar de pila...).

Por otro lado, aunque al hablar de uni dades fraseológicas, nos referimos a la fijación como una de sus car acterísticas fundam entales, esta fijación, com o ya he avanzado, no implica inmutabilidad; por ello, prestaré atención a los casos de variación fraseológica (Ortega Ojeda y González Aguiar, 2005: 92) ${ }^{3}$ y apuntaré los cam bios

\footnotetext{
${ }^{3}$ Estos autores definen la variación fraseológica como «el fenómeno que se produce cuando una UF, a pesar de estar fijada, se materializa en "formas distintas" sin que dicho cambio conlleve alteraciones en el significado fraseológico».
} 
sufridos por algunas de las locuciones ana lizadas, m uchas de las cuales han llegado hasta nuestros días.

2. Usos literales y usos figurados. Corpus de locuciones.

Como era de esperar, algunas de las unidades analizadas se usan, junto con su valor figurado, con un significado literal. De hecho, en los textos de los prim eros tiempos es este valor el que predomina y es necesario rastrear los casos de uso figurado. Véanse, en este sen tido, ejem plos com o los siguiente s, en los que solo es posible extra er u n significado literal:

1. E alegrad el rostro e abrid la mano e cobrare des la bienque rençia. ( 1471 - 1476, García de Salazar, Lope: Istoria de las bienandanzas e fortunas)

2. E al deseo que avién de llegar ayudó el buen tiempo, e por eso dize que ovieron viento en popa concorde a su dezir, fasta que lleg aron a pu erto de Candía. (1427 - 1428, Villena, Enrique de: Traducción y glosas de la Eneida. Libros I-III) ${ }^{4}$

3. E en el tiempo del señorío de Claudio acaeció por ventura que un pastor de Getulia echó la capa sobre los ojos a un león que vinié contra él, e prisol por esta guisa, e fizo d'él lo que quiso. (1275, Alfonso X: General Estoria. Primera parte)

4. Porque Gayo Galicula, entre sus muy torpes fechos, echó redes de oro en el mar Océano e en las monterías usava de increíble aparato. (1459, Palencia, Alfonso de: Tratado de la perfección del triunfo militar)

5. Alguna vez vi ene del pulmon, \& 1 a san gre que sale de la boca es llen a de espu ma, (1494, Burgos, Fray Vicente de: Traducción de El Libro de Propietatibus Rerum)

Con todo, $\mathrm{s}$ on $\mathrm{m}$ uchos los ejem plos de locuciones que aparecen en nuestros textos desde antiguo y a estos usos figurados, que constituyen una parte esencial de la lengua española, destinaré las próximas páginas.

Para elaborar el corpus de ejem plos, he partido, por una parte, de la nóm ina que Covarrubias (1611) recoge en su obra y, por otra parte, me he basado en las expresiones recogidas en Forment (1999), en Seco y Andr és (2004), en Ramos y Serradilla (2000) y en Serradilla (2004 y 2006). A continuaci ón, he hecho búsquedas en el CORDE de expresiones for madas por los siguientes verbos: abrir, cerrar, subir, bajar, caer, ir,

\footnotetext{
${ }^{4}$ E 1 s intagma "viento en popa" ap arece co n verbos como auer, navegar, llevar, venir... siem pre con significado literal, el primer ejemplo que he podido localizar de ir viento en popa con valor figurado se retrasa hasta finales del siglo XVI: Servicial es vuestro amor, / y aun servicio puede ser, / pues que se da a conocer / muy tan a lo servidor; / viento en popa va, señor, (bien os po déis ani mar, (1585 - a 1643 , Salinas, Juan de: Poesías).
} 
salir, entrar, andar, echar, llevar, sacar, meter, venir y volver, todos ellos incluidos en el grupo de verbos de movimiento. ${ }^{5}$ He marcado una limitación temporal que va del año 1100 al año 1499, la cual, aunque no deja de se r arbitraria, engloba unos siglos en los que la lengua sufre importantes cambios en todos los niveles.

En un principio, com o he señalado, lo s usos figurados son $\mathrm{m}$ uy escasos; de hecho, no es hasta el siglo XV cuando em pezamos a encontrar con cierta frecuencia estas locuciones en los textos. En los prim eros documentos, por el contrario, el lenguaje coloquial tiene una $m$ enor cabida en la es critura, aunque eso no quiere decir, co mo ahora comprobaremos, que estas fras es hechas no aparezcan dispersas en distintos tipos de tex tos d esde épo cas bien tem pranas. En todo caso lo que es evidente es que no sabemos en qué m omento nace un a unidad fraseológ ica. Hace ya más de 25 años, Tristá Pérez (1985: 74) decía:

\begin{abstract}
Resulta verd aderamente difícil determin ar el momento en que fue cr eado un fraseologismo. Excepto en los casos de frases proverbiale s, su entrada y asentamiento en la lengua se realiza de una forma sutil, sin que quede registrado cómo, dónde y en q ué momento surgi ó. Los creadores de la mayoría de est as unidades son desconocidos. Por lo general son creación del pueblo, manifestación de su sabiduría y su intuición lingüís tica. En muchas encue ntran reflejo la $s$ tradiciones, costumbres y creencias de un pueblo dado.
\end{abstract}

En la misma línea, añaden Echenique y Martínez Alcalde (2003: 235):

Lo cierto es que la fraseología tiene su origen en el habla y se consolida después en el sistema; las unidades fraseológicas han sido antes creación y luego evolución. La única manera de detect ar la génesis y el desarrollo de un buen nú mero de ellas es rastrear el entorno social en el cual se produjo.

\footnotetext{
${ }^{5}$ Est a nóm ina po dría ha berse vi sto i ncrementada c on ot ros ver bos de m ovimiento tales com o correr, llegar, pasar, partir, tornar, traer... La razón por la que han quedado fuera de este estudio es que, aunque algunos de el los pa rticipan en ex presiones fi guradas desde ant iguo: correr la cortina, pasar por la cabeza, traer la mano blanda..., en general, su productividad en este sentido es menor a la de los verbos analizados. Entre $m$ is próxim os proyectos figura uno más ab arcador co $n$ un alcan ce cro nológico más amplio que dé cuenta también de estos verbos.
} 
No pretendo, pues, realizar en este trabajo un estudio sobre la fecha de aparición de las lo cuciones analizadas ni tampoco, ya que sería im posible, ser exhaustiva en cuanto al número de locuciones presentes en nuestra lengua desde la época de inicios; es seguro que hay $\mathrm{m}$ ás expresiones con estos ve rbos pero intentaré dar una $\mathrm{m}$ uestra lo suficientemente ilustrativa de cuál era su situación en el español medieval a través de textos que nos permitirán observar el contexto si no en el que nacen esta s expresiones, sí, al menos, en el que se consolidan.

A continuación, se presenta la nómina de construcciones analizadas: ${ }^{6}$

ABRIR: abrir puerta, abrir tienda, abrir el ojo, abrir los ojos, abrir la boca, abrir camino, abrir mano / abrir la mano.

CERRAR: cerrar los ojos, cerrar la puerta, cerrar bocas, cerrar las orejas.

BAJAR:

SUBIR: ${ }^{7}$

CAER: caer amor, caer en el vicio, caer en peligro, caer en la red, caer en el yerro, caer en olvido, caer de pies, caer en gracia, caer enfermo, caer en el lazo/ caer en mal lazo, caer como de entre las manos, caer de espaldas.

\footnotetext{
${ }^{6}$ Covarrubias (1611) p resenta en su obra otras expresiones i diomáticas que no he documentado en el corpus analiza do; en este ca so podem os pensar que s on de entra da posterior en nuestra lengua; que , aunque existieran, no habían pasado a la lengua escrita o, simplemente, que están en textos medievales con los que no he trabajado. Las expresiones a las que me refiero son, entre otras, las siguientes: abrir la cabeza, abrir el cuello, abrirse en las razones; cerrarse de campiña, cerrarse la mollera, cerrar la cuenta, cerrarse las velambres, cerrarse las heridas; bajar la cabeza, bajar el tono, bajar el halcón de carnes, bajar de punto, bajar las calzas; subir al cielo sin escalera, subir el humo a la chimenea, subirse el humo a las narices, subírsele la mostaza a las narices, subirse en el canto subirse de punto; caer del cielo lanzas, caer de pies como gato, caer a mano; ir hombro con hombro, irse de lengua, ir mano a mano; andar en piernas; hechar los hígados, echarse un cántaro de agua a pechos; entrar con pie derecho; llevar el bocado de un carrillo a otro, llevar a hombros; volver una persona a manos de alguien; venir puestas las manos, venir con la lengua de un palmo...

${ }^{7}$ Quiero destac ar que con los verbos bajar y subir no he e ncontrado expresiones figuradas anteriores al siglo XVI. En ép ocas po steriores sí participarán en ex presiones con orientación n egativa y p ositiva respectivamente (Serradilla, 2004 y 2010).
} 
IR: ir de mal en peor, ir a mesa puesta, ir por lana y venir sin pluma, ir por lana y venir trasquilado, ir a la mano, irse de entre las manos, írsele por pies.

VENIR: venir en olvido, venir en amores, venir en rostro, venir en miente, venir en tierra, venir a mano, venir a la mano, venir algo/alguien a las manos, venir con mano armada, venir por las espaldas.

ANDAR: andar a monte, andar a casa y a monte, andar a gatas, andar a grillos, andar a pie, andar a rabo de borrega, andar a toma el cuerno, andar a vara, andar de puerta en puerta, andar de boca en boca, andarse con las cuentas en la mano, andar de boda en boda.

ECHAR: echar a las espaldas, echarse de rostros, echar de seso, echar de cabeza, echar a fondo, echar cantos, echar suertes, echar la mano (a/en), echar mano a algo/alguien, echar mano de algo/alguien, echar mano en algo, echar mano por algo, echar fama, echar la cuenta, echar el sello, echar del mundo, echar el bastón, echar el cordel, echar por tierra.

LLEVAR: llevar en braços, llevar la flor y la rama, llevar camino, llevar al cabo, llevar en los hombros, llevar las manos en la cabeza.

METER: meter a escusañas, meter a saco mano, meter voces, meter en baraias / meter baraias, meter en (la) muda, meter espanto, meter fuego, meter sed, meter a los miedos / meter miedo, meter amor, meter mientes / mentes, meter la cara, meter manos sobre algo, meter por mano, meter a la parte, meter la mano en el fuego.

SACAR: sacar de cordura, sacar de pila, sacar de trabajo y peligro, sacar algo de mano de alguien, sacar de entre las manos.

SALIR: salir con su intención, salir de seso, salir a plaza, salir de entre las manos, salir de la boca.

ENTRAR: entrar de golpe, entrar de rondón, entrar por la manga y salir por el cabezón.

VOLVER: volver los ojos atrás / volver atrás los ojos, volver los ojos, volver la hoja, volver(se) los colores, volver (la ) cara, volver el rostro, volver (las) espaldas, volver la cabeza, volver las riendas, volver el bulto, volver palabras, volver ruido. 
Como puede observarse, el grado de productividad de estos verbos para transponerse metafóricamente es diferente. También habrá diferencias importantes a lo largo de la historia, pues, como puede observarse en Se rradilla (2004 y 2010), verbos como ir, caer, subir y bajar son hoy enormemente productivos para constituir unidades fraseológicas, mientras que estos d os últimos, quizás por $\mathrm{s} u$ valor $\mathrm{m}$ ás concreto, $\mathrm{m}$ ás específico, no entran en locuciones en la épo ca m edieval. Otros verb os com o venir, andar, echar, meter o volver han continuado su andadura y durante toda nuestra historia lingüística han form ado y siguen form ando parte de nuestro universo fraseológico con muchísima frecuencia, por lo que es relativam ente fácil ra strear su presencia en los textos de todas las épocas.

Esta facilid ad para convertirse en la base de UFs hay que buscarla en la capacidad de estos verb os para ex tenderse metafóricamente de $\mathrm{m}$ anera que pasan de designar un $\mathrm{m}$ ovimiento real a designar un movimiento figurado y esto se da en prácticamente todas las lenguas (S erradilla, 2010). ${ }^{8}$ Este d esplazamiento sem ántico, como se puede observar en los ejemplos que se m uestran a continuación, no es de la misma naturaleza en tod os los casos; así, se pres entan ejemplos en los que el valor del verbo está m etaforizado pero es deducible de las unidades que co mponen la expresión (por ejemplo, en el caso de caer: 22, 23, 24, 25, 28 o en el de venir 51...); también se observan casos en los que es la complem entación del verbo la que aporta el sentido figurado (véanse los ejemplos 139 o 140 de entrar) y otros muchos ej emplos en los que el grado de m etaforización de la expresión es tal que hace que esta sea absolutam ente opaca (39 ir por lana y venir trasquilado, 46 salir a plaza, 68 andar a rabo de borrega...). Se trata de grados diferent es de des plazamiento semántico ${ }^{9}$ pero en todos los casos podemos hablar de uso figurado de la expresión.

\footnotetext{
${ }^{8}$ Productividad de est os verbos para entrar en UFs en es pañol medieval: abrir: 8; cerrar: 4; bajar: 0; subir: 0; caer: 13; ir: 7; venir: 10; andar: 12; echar: 19; llevar: 6; meter: 18; sacar: 5; salir: 5; entrar: 3; volver: 12.

${ }^{9}$ Agradezco mucho a uno de los evaluadores la información sobre el diferente grado de desplazamiento semántico que sufren los verbos que constituyen estas unidades fraseológicas.
} 
3. Análisis de la documentación medieval

En este apartado se m uestra un $\mathrm{p}$ anorama de la fraseo logía m edieval con verbos de movimiento; con el fin d e no alarg ar excesivamente este trab ajo, limitaré el número de documentos y, salvo en casos que presenten dif erencias significativas, solo in cluiré un ejemplo por expresión.

\section{1. abrir}

El verbo abrir entra desde antiguo en expresiones figuradas com o las siguientes: abrir puerta, abrir tienda, abrir la boca, abrir camino, abrir el ojo / abrir los ojos, abrir mano / abrir la mano. Obsérvese c ómo en las últim as se percib e ya la posibilidad de variación fraseológica, bien en el caso de la variación en el núm ero, bien por la presencia/ausencia de artíc ulo. Recordem os que, com o di ce Montoro del Arco (2006: 66), "Parece claro, pues, que las unidades fr aseológicas deben tene r fijación en algún grado para ser consideradas como tales, pero no es menos cierto que la inmensa mayoría de ellas experim enta algunos cambios o pue de tener formulaciones diversas al ser actualizadas en el discurso".

6. la perse uerancia que t ouo en la vi da virtuosa le abrió puerta para ent rar en grandes lugares, (1486, Pulgar, Hernando del: Claros varones de Castilla)

7. E fizose que el yendo en rromeria al grand tenplo delas arenas que oujera tormenta \& que le falle ieran las vituallas \& que abriera ally tienda a ven der de sus Joyas por conprar delas viandas E por quanto el auja promesa de n on salyr en tierra fasta que al tenplo allegase por ende abria tienda enla gal ea \& en esta galea entra uan muchas personas a $\mathrm{m}$ jrar de los de a quella ibdat \& conprauan cada vn o de lo que le plazja (c 13 50, Anónimo: Sumas de la historia troyana de Leomarte)

8. ay muchas baxas en a quella comarca, y conviene abrir el ojo hasta entrar en el puerto; (1492 1493, Anónimo: Diario del primer viaje de Colón)

9. vos otros señores que tenedes los altos ynperios abrid los ojos E ensanchad las orejas E por que sueño mortal non vos tome vel ando ot ead por quanto \& quales dados de la fortuna tengades adversidad co ntra $v$ os $E$ pa rad $m$ jentes que a 1 as fuerç as del la non bastan $p$ ara $R$ esistir 1 os consejos humanos (1402, López de Ayala, Pero: Caída príncipes)

Querría hacer un brevís imo comentario ace rca de la locución m ostrada en (9). Por lo que se desprende de la docum entación, en los prim eros usos figurados de esta expresión el sustantivo ojos aparece siempre modificado por un adjetivo relacional o un sintagma preposicional. Así, se especifica que se abren los ojos del espíritu, de la 
voluntad, $\mathrm{d}$ el entendim iento, del cuerpo...; con ello $\mathrm{p}$ arece que el prim er valor metafórico se adquiere con el complemento del nombre:

10. E porque el que en este mundo biue sienpre es conbatido de tres espeçiales enemigos, los quales son el diablo e el mundo e la carne, e por ende ha menester que estes sienpre aperçebido para te defender dellos, e avn pa ra los vençer e ferir e echar de ti. Por e nde, abre los ojos corporales $e$ spirituales e vee e oye e entiende e a prende $\mathrm{m}$ is castig os (1293, Anónimo: Castigos e documentos)

11. desechada de sy toda pereza que luenga mente avia husado abrio los ojos de la voluntad $\mathrm{E}$ veyendo ya el tiempo pasado... (1402, López de Ayala, Pero: Caída príncipes)

\section{Abrir la boca significa desde antiguo 'hablar' pero se observa ya tam bién en la}

época medieval el significado de 'bostezar' (13), que ha pervivido hasta nuestros días:

12. Et non aure yo muy gran(n)t Verguença quando fuere ante mjramoljn \& non osar tan sola mente abrir la boca njn dezjr esta villa /o este Castillo tome yo(n) njn este bien fize yo en mj cabo con los mjs vasallos (1344, Anónimo: Crónica de 1344)

13. \& delos verbos compuestos vno dellos es oscito. tas. aui. que significa abrir la boca o boçezar que dezimos nos otros en vulgar. (1490, Palencia, Alfonso de: Universal vocabulario en latín y en romance)

14. E por que si a este se diesse lugar, seria abrir camino a mayores in conuenientes, ( 1484 , Anónimo, Fernando ruega al cardenal de Nápoles haga desistir... $)^{10}$

15. Et seg uro seed sennor que redes muy bien de no abrir mano de fecho de 1 os moros. (1314, Anónimo: Carta de Diego García excitando al Rey de Aragón a continuar...)

16. El segundo pecado mortal es avariçia. En é ste, ¿quién dubda sy pecan a quellos que en ora mala aman? Non son contentos de quanto tyenen; non los fartaría la mar por a ndar locos e a rreados, por fazer justas e meneos. E jamás verás a ni nguno abrir la mano a fazer franqueza synón a su coamante, o a los que lo tract an o saben * o son alcahuetes o mensajeros della. or fazer justas e meneos. (1438, Martínez de Toledo, Alfonso: Corbacho) ${ }^{11}$

\section{2. cerrar}

Aunque no de for ma tan habitual, tam bién cerrar participa en unidades fraseológicas como las siguientes: cerrar los ojos, cerrar la puerta, cerrar bocas, cerrar las orejas.

17. sant Gregorio dize que dormir en el camino es apartarse onbre en esta presente vida de sus cosas tenporales e dormir en el ca mino es cerrar los ojos dest as cosas pasa deras; ( $1474-15$ 00, Villalpando, Antonio de: Razonamiento de las Reales Armas de los Católicos Reyes)

\footnotetext{
${ }^{10}$ Esta locución presenta regímenes muy variados. Véase el siguiente ejemplo con la preposición de: $\mathrm{Ca}$ de ot ra manera no se ria si no abrir camino de distroyr 1 a rel igion de Sant Jo han, ( 1483, A nónimo: Fernando al pronotario Borja).

${ }^{11}$ Se $\mathrm{t}$ rata de una e xpresión frecue nte e $\mathrm{n}$ los te xtos medievales pero casi siem pre apa rece $\mathrm{c}$ on un significado literal, no con el figurado que se observa en este ejemplo.
} 
18. ... de tal $\mathrm{m}$ anera que la graueza del delito les cerrasse la puerta de la esperança para ser perdonado (1486, Pulgar, Hernando del: Claros varones de Castilla)

19. mas quexo me con todo del tanto poder dela inuidia: que pudo cerrar tantas bocas delos tantos: que vieron aquel que subio primero enla cerca. y assi enmudecieron que nunca en tan buen fecho fablaron. Se que si castellano fuera portogues: o de otra parte: no passara tan por silencio. mas los de nuestro Aragon tanto saben del bien obrar: que se les oluida luego del saber lo dezir: ni querer lo fablar. (1499, García de Santa María, Gonzalo: Traducción de la Corónica de Aragón de fray Gauberto Fabrici)

20. SEMPRONIO. (Maldiciente venenoso, ¿por qué cierras las orejas a lo que todos los del mundo las aguzan, hecho serpiente que huye la voz del encantador? Que sólo por ser de amores estas razones, aunque mentiras, las habías de escuchar con gana.) (c 1499 - 1502, Rojas, Fernando de: La Celestina) ${ }^{12}$

\section{3. caer}

Respecto a caer, es frecuente que los usos figura dos aporten un $\mathrm{m}$ atiz negativo pues responden a la metáfora universal "abajo = negativo" (Serradilla: 2004). Respecto a este punto quiero señalar que, en todo caso, co mo afirman Pamies, Lozano y Cortina (2008: 284), aparte de los universales fraseológ icos “[ [... otra i mportante faceta de la comparación fraseológica interling üística qued a fuera del alcance de los $\mathrm{m}$ ismos: la herencia cultural". Este es un trabajo de corte intralingüístico, pero tam bién, obviamente, se tiene en cuenta la herencia cultural que es la que en m uchos casos nos permite entender m uchas locu ciones ( caer de pies como un gato, por ejem plo). En el caso de caer, no obstante, como señalo arriba, la metáfora universal parece funcionar de manera general: caer en el vicio, caer en peligro, caer en el yerro, caer en olvido, caer enfermo, caer en la red, caer en el lazo/ caer en mal lazo, caer de espaldas, caer como de entre las manos... aunque eso no obsta para que sea posible encontrar unas pocas excepciones que no tienen este valor: caer amor, ${ }^{13}$ la mencionada caer de pies o caer en gracia.

21. Puede caer amor entre dos sabios por que se semejan en los sesos, e non puede caer amor entre dos locos, maguer que son semejables en la locura; por que el seso es segunt orden, pues puedense acordar en ello dos e n una carre ra; e la locura non a nda segunt orden, pues non puede caer acordamiento en ella entre dos. (a 1250: Anónimo: Bocados de oro)

\footnotetext{
${ }^{12}$ C ovarrubias define esta expresión como 'no a dmitir razó n'; tam bién en los ejem plos docum entados significa 'no escuchar'.

${ }^{13}$ Aunque quizás en este caso no se vea como algo positivo. La idea de que se cae en el a mor es común a otras lenguas y se mantiene hoy en día, por ejemplo, en inglés: to fall in love.
} 
22. por lo qual y por no caer en el vicio de ingratitud, si tú quieres ir al to rneo, yo te daré cavallo y armas (1499, Anónimo: La historia de los nobles caballeros Oliveros de Castilla...)

23. Y est e en xemplo vos dó porque los criados han de faz er que se guarden, que no caigan en peligro por no castigar sus criados, assí como acontesció a Elí (1300 - 1305, Anónimo: Libro del cavallero Cifar)

24. E esto es de s saber por non caer en el yerro de la euacuaçion ssuperflua. (1400, Estéfano de Sevilla: Visita y consejo de médicos)

25. E por non caer en olvido le mandaron los reyes pon er en escr ito (1287, An ónimo: Privilegio rodado de Sancho $I V$ )

26. La virt ud, asy com o el filos ofo dize, sie npre cae de pies como el abrojo. (a 1424 - 1520, Anónimo: Cancionero de Juan Fernández de Íxar)

27. Esto hizo con tan buena maña y denuedo que cayó en gracia al Rey y le mandó vivir consigo (c 1492, Maldonado, Alonso, Hechos del Maestre de Alcántara don Alonso de Monroy)

28. Decultarunt. m ucho oc uparon. Decumbere. caer enfermo. ( 1490, Palencia, Al fonso de: Universal vocabulario en latín y en romance)

29. Ca tan bien los que fazen los remedijos \& los escarnios. cuemo los que se delectan en los oyr. \& les dan por que los fagan; caen en la red del diablo. (1256 - 1263, Alfonso X: Primera Partida)

Obsérvese cóm o el valor negativo de caer en el lazo se ve reforzado c on la incorporación de palabras negativas como mal lazo o lazo del diablo:

30. Mio fijo, guardate que te non vezca $n$ cosas sabrosas e fe rmosas, ca aquellas son las que faze $n$ caer al omne en mal lazo. Las artes non caerian en la red que les arman si non fuese por el çeuo que les y echan, ca tan grande es la sabor que toman de com er aquel çeuo que se non guardan con cuyta dello de caer en la red, e $\mathrm{n}$ on se sienten del su $\mathrm{m}$ al fast a que $\mathrm{l}$ a red $\mathrm{t}$ ienen desu so. (1293, Anónimo: Castigos e documentos)

31. que aquel que entiende en rriquezas ayuntar, cae en el lazo del diablo, en muchos deseos malos (a 1448, Anónimo: Traducción del Libro de las donas de Francesc Eiximenis)

32. Los unos e los otros cerca eran del plazo, / ca ya era venida la ora del porfazo, / quál de ambas las partes caerié en el lazo, / quál podrié a la otra sovar el espinazo. (c 1230, Berceo, Gonzalo de: Vida de San Millán de la Cogolla)

33. Así que contigo se te caían como de entre las manos señales muy claras de pena. (c 1499 - 1502, Rojas, Fernando de: La Celestina) ${ }^{14}$.

34. \& estando aun en pie. cayo de espaldas. sobre la finiestra del palacio. (1293, Anónimo: Gran Conquista de Ultramar)

3.4. ir

Ir es un verbo infraespecificado que, c on frecuencia, participa en unidade $\mathrm{s}$ fraseológicas: ir de mal en peor, ir a mesa puesta, ir por lana y venir sin pluma, ir por lana y venir trasquilado, ir a la mano, irse de entre las manos, írsele por pies. Dice Covarrubias (1611): «O tras fórmulas hay del verbo ir; déjolas por no cansar», lo que

\footnotetext{
${ }^{14}$ El sintagma "de entre las manos" aparece también en la época analizada con los verbos sacar, salir e ir. Se trata de otro caso más de variación fraseológica.
} 
nos permite pensar en la enorme productividad de este verbo para constituir expresiones figuradas en español desde antiguo.

35. fueron vençidos. E el cónsul, vista así la cosa ir de mal en peor, a 1 a po stre perdida toda la esperança (1471 - 1476, García de Salazar, Lope: Istoria de las bienandanzas e fortunas...)

36. mayormente tú que vas a mesa puesta. SEMPRONIO. Otras cosas he menester más (1499 1502, Rojas, Fernando de: La Celestina)

La siguiente expresión la recoge Covarrubias como ir a vela tendida o remo; en los textos medievales lo que encontramos es una variación con el verbo pasar:

37. Ca sy las fablas vigor / han como tu la demuestras / alas anjmas synjestras / es tal terror o temor / non a mj ca yo non temo / sus tormentos / mas pasar con los esentos / a vela tendida o Remo (c 1430 - a 1480, VV.AA.: Cancionero de Salvá)

Una de las características de las UF s es su fijación $\mathrm{p}$ ero, com o estam os observando, son m uy frecuentes lo s casos de variación; véan se, en este sentido, los siguientes tres ejemplos: el significado de la locución es el mismo pero hay importantes diferencias formales: ${ }^{15}$

\footnotetext{
${ }^{15}$ Est a UF c ontinúa su va riación a 1 o 1 argo de 1 a hi storia y y a en el si glo XVI enc ontramos nuevas variantes como venir por lana e ir trasquilado, venir por lana y volver trasquilado, llevar lana y volver trasquilado, sacar lana y hallarse trasquilado, ir por la lana y tornar trasquilado (explicada por Valdés), ir por lana y salir trasquilado o la más frecuente hoy en día: ir por lana y volver trasquilado, que incluso es definida ya por Fray Bernardino Sahagún en una de sus obras. Él no fue ladrón; antes venía por lana y fue trasquilado, y por m ucho madrugar no le am anesció más aí na. (1 550, Arce de Otárola, Jua n de: Coloquios de Palatino y Pinciano); dirian que auiades ydo por lana y bueltos trasquilados. (1552, Núñez Alba, Diego: Diálogos de la vida del soldado); T. Más os valiera callar, pues, "yendo por la lana, avéis tornado trasquilado". M. Assí es verdad que torno trasquilado, pero también llevo lana, pues he sabido lo que hasta ag ora no sa bía. ( 1535 - 1536, Valdés, Juan de: Diálogo de la lengua); di cho Rey Don Juan penso venir por lana y voluio trasquilado. (15 16, A nónimo: C édula de 1 os R eyes Doña J uana y Do $n$ Carlos); crey eron llevar lana y volvieron trasquilados, porque perdieron muchos las vidas y más de 1 a mitad de 1 as c anoas que traían, y otros muchos volvieron heridos (c 1568 - 1575, Díaz del Castillo, Bernal: Historia verdadera de la conquista de la Nueva España); Y de la esperança vana Inducidos y engañados, Do pensaron sacar lana Se hallaron trasquilados, (15 47, Castillejo, Cristóbal de: Aula de cortesanos); Y algunos que van por lana Y al fin salen trasquilados. (1547, Castillejo, Cristóbal de: Aula de cortesanos); "Yva por lana y [b]o[l]ví trasquilado, y tropecé en la piedra". Este refrán se dize del que iva a ne gociar alguna merced con al guna persona de manera y cayó en s u desgracia, y no recabó nada.
} 
38. SEMPRONIO. Madre, mira bi en lo que haces, porque cuando el principio se yerra, no puede seguirse buen fin. Piensa en su padre, que es noble y esforzado, su madre celosa y brava, tú la misma sospec ha. Melibea es única a ellos; faltán doles el la, fáltales todo el bien; en pensallo tiemblo; no vayas por lana y vengas sin pluma. CELESTINA. ¿Sin pluma, hijo? SEMPRONIO. O emplumada, madre, que es peor. (1499 - 1502, Rojas, Fernando de: La Celestina)

39. Fué por lana y vino trasquilado. 195. Fartadme y echadme, si n on dormiere matadme (c 1450, Anónimo: Seniloquium)

40. Ca le contesçi o / sse gund diz el prouer bio commo / al ca rnero ençençerrado que va / buscar la lana \& viene trasquilado. (a 1325, Anónimo: Crónica de veinte Reyes)

En los estudios de fraseología se m enciona frecuentem ente el concepto de desautomatización:

Se trata de 1 a manipulación o m odificación creativ a voluntaria de una UF, por medio de la cual el hablante libera el lenguaje de su automatismo interpretativo y con la que persigue conseguir determinados efectos de tipo pragmático (expresivos, humorísticos, etc.) (Montoro del Arco 2006: 43).

Así, Forment (1999) señala cóm o el hablante puede cam biar algún elem ento de la frase hecha en el discurso y, cuanto más fijada está la frase, más útil será este recurso. Echenique (2003: 555), por su pa rte, propone ejemplos com o estar de mal yogur; ojos que no ven, gabardina que se llevan... Usos co mo estos, $m$ ás propios, quizás, de la oralidad, no se documentan aún en los textos medievales, excepto en el caso de de ir por lana y venir sin pluma donde, incluso, se extraen elem entos de la UF para darles otro papel en el discurso. E 1 ejem plo encontra do, de hecho, es el único docum entado en CORDE, y esto nos perm ite sospechar que se trata de un juego, de un proceso de desautomatización, por parte del autor.

A continuación, $\mathrm{m}$ e detendré en la locución ir a la mano, que pres enta en los textos medievales una gran polisemia; así, en (41) hace referencia a un lance del juego; en (42) sig nifica 'ac ercarse', 'se r sim ilar' o, com o decía Covarrubias, 'repo rtarse', mientras qu e en (43) tiene el valo $r$ de 'e nfrentarse' o en pala bras de Covarrubias: 'estorvarle y contradezirle':

41. E estos tractan de las sotileza s que conuj enen al juego. \& de com o se fazen los dados falsos. \& que modo deuemos tener en el yr / a la mano. \& cet era. para ganar con tuerto. (1454, Chirino, Alfonso: Espejo de medicina)

(1576 - 1577, Sahagún, Fray Bernardino de: Historia general de las cosas de Nueva España). Obsérvese que en todos los casos se sigue recurriendo a verbos de movimiento. 
42. Mas solamente mortificaçión de las fuerças corporales, es la [q]ue va a la mano a e stos vanos pensamientos y los afloxa y haze queda $r$ en grand grado desmayados (1455 - 1460, Cartage na, Teresa de: Arboleda de los enfermos)

43. Ca sy quiero oýr, non me lo consyente; e sy fablare, vame a la mano, e claramente me dize no ser otra su yntinçión sinon [deuedar] lo que qui ero y hazerme querer lo que n o quiero. Lo que quiero es e nboluerme en 1 as ocu paçiones mundanas e 1 o que no quiero es 1 a sol edat o apartamiento de todo ello. Pues bien mirada su yntinçión, mejor es que no la mía; (1455 - 1460, Cartagena, Teresa de: Arboleda de los enfermos)

Detengámonos en el siguiente ejemplo:

44. Alisa, amiga, el tiempo, según me parece, se nos va, como dicen, de entre las manos; corren los días como agua de río. (1499 - 1502, Rojas, Fernando de: La Celestina)

Se trata de un docum ento m uy interesa nte: ob sérvese có mo en la expresión "como dicen" hay una referencia a que ya en la época los hablantes consideran esta

locución como una frase idiomática (con el valor de 'escabullirse').

45. En mi jovent ud caça por pies non se me iva, / a m i señor la dava quier muerta o quier bi va: $(1330 \text { - 1343, Arcipreste de Hita: Libro de buen amor })^{16}$

3.5. salir

También salir entra en unidades fraseológ icas: salir con su intención, salir de seso, salir a plaza, salir de entre las manos, salir de la boca.

46. Asimesmo era om e que, da do que oviese algunos ynconvenientes en las cosas que c omençaua, sienpre que ría salir con su yntinçión, e llevar adelante su s p ropósitos (1480 - 1484, Pulgar, Hernando del: Crónica de los Reyes Católicos)

47. CELESTINA. ¿Qué tercia parte? ¡Vete con Dios de mi casa tú, y esotro no dé voces, no allegue la vecindad! No ne hagáis salir de seso, no queráis que salgan a plaza las co sas de Calisto y vuestras. (c 1499 - 1502, Rojas, Fernando de: La Celestina. Tragicomedia de Calisto y Melibea)

48. e dixe entre mi mesma que pues todos beuian de a quella fuente que bien me podria bengar de mis enemigos entonçe eche enla fuente vna Redoma llena de vn $m$ uy fuerte veneno de que fue luego la fuente enponçoñada asi que nunca ome despues della veuio que no fuese luego muerto ansi que en tres dias murieron delos dela hueste mas de quinze mill en tal manera que hubieron de dexar la çerca e se fueron todos dela tierra e quando nos aquello vimos fuimos muy alegres e dixe a my padre como yo aquello auia fec ho Por la fuente que a uia yo enponçoña do e acaesçio

\footnotetext{
${ }^{16} \mathrm{C}$ on el si gnificado de 'huir'. Se a plica t ambién a pe rsonas; véase el siguiente ejem plo: AREÚSA. Hermana, no seamos nosotras lastimeras. Haga lo que quisiere; mátele como se le antojare. Llore Melibea como tú has hecho; dejémosle. C enturio, da buena c uenta de 1 o e ncomendado; de cual quier m uerte holgaremos. Mira que no se escape sin alguna paga de su yerro. CENTURIO. Perdónele Dios si por pies no se me va. (1499 - 1502, Rojas, Fernando de: La Celestina)
} 
que esto que lo sopo el Rey badalon e ovo tan gran duelo que quiso salir de su seso e dixo que no abria Plazer fasta que se vengase (1414, Anónimo: Traduccción de Lanzarote del Lago)

49. Cierto -dixo ella- esto no entró en la pleitesía, ca mi prisionero es \& yo lo devo soltar quando yo quisiere, ca no quer ría que se me saliesse de entre las manos por alg una arte. (1300 - 1305, Anónimo: Libro del cavallero Cifar)

50. Mas desenbargadamente $\&$ por ende todo onbre \& mayor mente el rey se deue mucho guardar en su palabra de manera que sea catada \& pensada ante que la diga. Ca pues que sale de la boca no puede onbre fazer que no sea dicha. (1491, Anónimo: Siete Partidas de Alfonso X)

3.6. venir

Venir es uno de los verbos m ás productivos para constituir UFs: venir en olvido, venir en amores, venir en rostro, venir en miente, venir en tierra, venir por las espaldas. Llama especialmente la atención la variación existente con el térm ino mano, tanto en el nivel m orfológico com o en el sem ántico: venir a mano / venir a la mano (Decía Covarrubias: 'es de caçadores de bolatería'), venir algo/alguien a las manos, venir a las manos ('empezar a reñir'), venir con mano armada ('es con gente para pelear o reñir').

51. La virtud memorativa es una potençia conservativa por la qual nos guardamos las espeçies de las cosas conçe vidas que no vengan en olvido \& 1 as po nemos \& guard amos en el thesoro de memoria, \& por est o dize un dotor, dicho Aviçena, que la memoria es arca o cofre de la razon. (1494, Burgos, Fray Vicente de: Traducción de El Libro de Propietatibus Rerum)

52. que quando los cavallos comiençan de venir en amores la boz les cre çe, (1494, Burgos, Fray Vicente de: Traducción de El Libro de Propietatibus Rerum)

53. El Clavero y los suyos pasaban hambre no sufridera: la gente, doliente de los malos manjares; los muros, por muchas partes rotos. Pues los del Maestre, en gran manera fatigados y aun d'esta postrera vez bien espantados; y como el invierno venía en rostro, el trabajo [era] insoportable [y] la vitualla muy poca; (c 1492, Maldonado, Alonso: Hechos del Maestre de Alcántara don Alonso de Monroy)

54. e echaron de la cibdat); e les dixo que les devía venir en miente de los reyes del tienpo passado (c 1400, López de Ayala, Pero, Taducción de las Décadas de Tito Livio)

55. E aqu í fueron d erribados por el su elo más de trezientos cavalleros. E conbatíanse a pie e a cavallo tan bravamente que mayor trueno davan los golpes que si un grand monte veniese en tierra. (1430, Corral, Pedro de: Crónica del rey don Rodrigo, postrimero rey de los godos)

56. Mucho se enfinge, * mas non me contenta / aqueste escudero, gentil sevillano, / en fazer dezires si l' viene a mano, segun t su çien çia g elo * representa; ( 1414 - a 14 35, Manu el de Land o, Ferrand: Poesías [Cancionero de Baena])

57. Otrosí, que no dará ni consentirá a sus o fiçiales que den dádiuas ni presentes, ni farán promesas de 1 es dar presentes a persona al guna de las que co ntinuamente resy den e n c orte, ni a sus mugeres ni fijos, ni a ofi çiales, ni a ot ras pers onas para que vengan a la mano de aquellas, directe ni yndirecte. (p 1480 - 1484, Pulgar, Hernando del: Crónica de los Reyes Católicos)

58. El Alm irante resçibió $\mathrm{m}$ ucho plazer y $\mathrm{c}$ onsolación d' estas cosas que vía, y se le te mpló el angustia y pena que avía r escibido y ten ía de la pérdida de 1 a nao, y cognosció que Nuestro Señor avía hech o en callar allí la n ao porque hiziese allí a siento. "Y a esto ", dize él, " vinieron tantas cosas a la mano, que verdaderamente no fue aquel desastre salvo gran ventura, porque es cierto", díze él, "que si yo no en callara, que yo fuera de largo sin surgir en este lugar, (1492 1493, Anónimo: Diario del primer viaje de Colón)

59. - Si más el enemigo me buscará, ¿qué faré y o mezquina? Respondióle El eastras: - En cobrirte has, e to dos dirán qu e er es muerta, que esa h ora quando v encieron e matar on lo s go dos e al generoso su rey mataron a ti. Dixo la Reina: - E ¿qué me aprovechará esconderme si yo he de 
venir a las manos de los e nemigos? (1430, C orral, Pe dro de: Crónica del rey don Rodrigo, postrimero rey de los godos) ${ }^{17}$

60. Yo non s oy rey, pero fijo soy de rey e el pecado de mi padre e de mi madre non es mío. E mi costunbre non es de contender en palabras sinon en fechos e vengamos a las manos e por allí se á de librar. (1471 - 1476, García de Salazar, Lope: Istoria de las bienandanzas e fortunas...)

61. Oh al ta b ondad de virtuoso Maestre, que conosçiendo que aquel Ga rçi Sánchez, d espués del ofresçimiento que fecho le avía de le servir, segúnd de suso es escripto, venía con mano armada contra él, non le pudo negar en tal tienpo el ofiçio de sus virtudes en lo perdonar, e non mandar proçeder nin usar contra él de pena alguna, nin de otro rigor (1453, Anónimo: Crónica de Don Álvaro de Luna)

62. estonce vino por las espaldas uno de los romanos desterrados que estava con los enemigos e dio de una lança al dicho Valerio, en manera que'l pasó de parte a parte; ca el dicho Valerio se avía puesto mucho adelante en la batalla; en manera que su cavallo non pudo retraer; (c 1400, López de Ayala, Pero: Taducción de las Décadas de Tito Livio)

\section{7. andar}

Andar es uno de los verbos con más facilidad para trasponerse a un significado figurado y eso provoca que desde antiguo sean muchas las locuciones españolas que cuentan con este verbo: andar a monte, andar a casa y a monte, andar a gatas, andar a grillos, andar a pie, andar a rabo de borrega, andar a toma el cuerno, andar a vara, andar de puerta en puerta, andar de boca en boca, andarse con las cuentas en la mano, andar de boda en boda. Algunas de ellas hoy nos resultan op acas pero otras seguimos utilizándolas en la actualidad con idéntico valor.

63. Amadís quedó en Gaula como oís, donde moró treze meses * y medio, en tanto qu'el rey Lisuarte tuvo el castillo del Lago Ferviente cercado, andando a casa y monte, que a esto más que a otras cosas era inclinado; (1482 - 1492, Rodríguez de M ontalvo, Garci: Amadís de Gaula, libros I y II)

64. Rey aduarte santo de yngla tierra que vna vegada andaua a monte con muy grand frio \& yendo el Rey... (1293, Anónimo: Castigos) ${ }^{18}$

65. La decrepita vejes / algunos quieren desir / que paresçe a la niñes / esto quiere consentir / que puede bien conuenir / quando al viejo alguna ora / anda a gatas e llora / cobdiçiat pues tal beuir. (a 1424 - 1520, Anónimo: Cancionero de Juan Fernández de Íxar)

66. Sabes sabes el modorro al la d onde anda a grillos burlanle lo s mançebillos (c 1464 - 1474, Anónimo: Coplas de Mingo Revulgo)

67. E asy se lofue don Hector para los suyos con aquellos dos cauallos e diolos luego a los primeros dos caualleros que vio andar a pie, e el fincose en Galatea, el su cauallo muy preçiado. (c 1270, Anónimo: Historia troyana en prosa y verso)

\footnotetext{
${ }^{17}$ Los ejemplos anteriores, pese a la va riación en el número y en el régimen, presentan todos el valor de 'ir a parar en algún sitio' 'llegar'; el siguiente tiene el valor de 'empezar a reñir', 'luchar'.

18 Se trata de una locución muy frecuente en la época medieval.
} 
68. Pelayo No con mis ojos. / Bras Ora sigue tus antojos, / que affición es que te ciega. / Tú sosiega. / no desm ayes con d olores, / que t anbién yo, por am ores, / ando a rabo de borrega. (1497, Encina, Juan del: Representación sobre el poder del Amor)

69. Fray Pedro de Bobadilla, / no o s hagáis sordo ni mudo, / que os tien en en esta villa / p or muy famoso cornudo; / b ien lo sab e el Provincial, / po rque desde aqueste invierno / yo y el n uestro mayoral / andamos a toma el cuerno./ Fray Pedr o Melén dez, cristiano, / m intió quien tal te dezía, / que el un cuarto es de m arrano / y l os tres de sodomía; / u n fraile me dixo anoche / (el nombre del cual te niego), / que en el mesón de Pedroche / fuiste novio de don Diego. (1465 1466, Anónimo: Coplas del Provincial)

70. E por sallir d e so el $\mathrm{m}$ andado de su padre o madre, marido o parientes, vanse e creen aq uellos que non solamente las mandan, más las farrean * como a bestias "¡Farre acá! ¡Farre acullá!", después quel amor pasado -que dura quanto más un año e ya es mucho sy tanto dura- e de allý adelante ¡vía andar a vara! E todo esto por amor de aquel que en verdad non pierde sueño nin comer por ella (1438, Martínez de Toledo, Alfonso: Corbacho)

71. e secarsele han las plumas al sol e andara de puerta en puerta e non le querra ninguno (c 1400, López de Ayala, Pero, Crónica del rey don Pedro)

72. ¡Oh mi triste nombre y fama, cómo andas al tablero de boca en boca! ¡Oh $\mathrm{m}$ is secretos... (c 1499 - 1502, Rojas, Fernando de: La Celestina. Tragicomedia de Calisto y Melibea)

73. La hermana, quando esto oyó, con grand ira respondió e dixo que ella tenía demonios, que usava vigardías; que ella, si mal hazía, que lo hazía de manera que todos lo sabían e que ella se andaba con las cuentas en la mano e con el diablo en el cuerpo e se echaba con el ombre bueno so color de ir e veni r a peni tencia. ( c 1400 - 1498, A nónimo: El baladro del sabio Merlín con sus profecías)

74. todos avién grand fiesta, fazién grandes ya ntares; / andan de boda en boda clérigos e juglares. (1330 - 1343, Arcipreste de Hita: Libro de buen amor)

\section{8. echar}

También echar presenta una enorm e productividad para entrar en expresiones con significado figurado y, de nuevo, llam a la atención la gran variación de fórm ulas en las que entra el térm ino mano: echar a las espaldas, echarse de rostros, echar de seso, echar de cabeza, echar a fondo, echar cantos, echar suertes, echar la mano (a/en), echar mano a algo/alguien (Covarrubias: 'asirle o prenderle') , echar mano de algo/alguien (Covarrubias: 'escogerle'), echar mano en algo, echar mano por algo, echar fama, echar la cuenta, echar el sello, echar del mundo, echar el bastón, echar el cordel, echar por tierra.

75. Las maldades agenas avemos ante 1 os ojos, e las nuestras las echamos a las espaldas. c 1430 , Anónimo: Floresta de philósophos) ('olvidar')

76. Estonçe el r rey Nabuca dnosor echose de rrostros, e a Dani el se om illo; (c 14 00, An ónimo: Biblia ladinada)

77. Policrato. Item el mismo, en el lib ro ya alle gado, capitulo XIIIo, faulando d'esta materia, dize que Ciçilio dixo assi n: $\mathrm{O}$ empera dor noble et paçient, tu fazes muchas valentias et prodezas et obras assenyaladas et muchas cosas mas has. En vna cosa empero apareçe en tu sauieza mas que en otras, como lagoteros non te han echado de seso, los quales, por tal que te pueden complazer, fazen i niuria a dios et a tu puebl o. (1376 - 1396, Fernández de Heredia, Juan: Libro de actoridades (Rams de flors)) 
78. por mostrarle sus possesiones, \& lo espenyo \& lo echo de cabeça ayuso sobre las piedras. (1379 - 1384, Fernández de Heredia, Juan: Traduccción de Vidas paralelas de Plutarco, III)

79. enuestieron la dicha carauela con lombardas y otras fuerças, la echaron a fondo, e tomaron parte de las ropas y mercadurias (1498, Anónimo: Don Fernando al embajador en Venecia...)

80. \& era ya a los griegos trabajo non poco de poder tornar los estrumentos a que tirasen menos njn mudar la manera del algarrada asy eran parados para tirar aluenne mas abondando les el pesso de lo que alcançauan que se fazie de alto contra ayuso tornaron a echar cantos a braços desnudos \& demjentra que toujeron a rmas or denadas as y com mo los techos de las casas da $\mathrm{n}$ p oco por el granjzo \& 1 o echan de sy pero suenan los techos. (a 1284, Alfonso X: General Estoria. Quinta parte)

81. el juez \& los alcalldes del anno passado escoianlo echando suertes sobre [f. $6 \mathrm{v}$ ] çinco caualleros de la collacion que sean buenos \& discretos, quales desuso dixiemos; (c 11 196, Anónimo: Fuero de Soria) ${ }^{19}$

82. Et pusieron una uara en esse Campo en m edio del cerco. Et dixieron que el que ue nciesse que fuesse luego echar la mano en aquella uara. \& di xiesse que a uie ue nçudo el cam po. (1270 1284, Alfonso X: Estoria de España, II)

83. el mato a todos fasta vno s olo. E como assi mesmo echasse mano a aquel para lo matar: dixo al carnicero... (a 1482, Anónimo: Esopete historiado) ('desenvainar la espada')

84. E estonçes abaxóse un poco el omne, e echól' mano de los cojones del ximio e a pretógelos (c 1253, Anónimo: Sendebar)

85. los geutauros entraron en el talamo del no ujo \& echaron mano dela nouja (c 1350, A nónimo: Sumas de la historia troyana de Leomarte)

86. amemos e 1 audemos todos a la Gloriosa; non echaremos mano en cosa tan preciosa, (1246 1252, Berceo, Gonzalo de: Los Milagros de Nuestra Señora)

87. viesse camino para fuirla, en comendándose a Di os echó mano por la espada y esperó la cruel alimaña. (1499, Anónimo: La historia de los nobles caballeros Oliveros de Castilla...) ${ }^{20}$

88. E dígolo por Arcanus que ha echado fama por el mundo que Lenbrot fue muerto (c 1430, Corral, Pedro de: Crónica del rey don Rodrigo, postrimero rey de los godos)

89. La segunda regla es que todo cuento que sube arriba de treinta e non allega a sessenta devemos sacar los treinta e dexar los otros fasta que lleguen a treinta. E después por las tres conjunturas que son en el dedo pulgar avemos de echar aquel cuento que sobra. Pero devedes notar que en la primera conjuntura faza el bra ço dezimos çinco, en la segunda quin ze, en la terçera veinte çinco puntos. Et ansí echada la cuenta de toda la suma, lo que queda de los añ os de J hesuchristo devémoslos ech ar por las d ichas co njunturas d el m esmo d edo. (1428, Villen a, En rique de: Tratado de Astrología ${ }^{21}$

90. Tyene u na c osa so bre t odos 1 os $r$ reyes y prí ncipes del $m$ undo: [Fol. XX XXr] que es ser byenquysto y amado de chicos y grandes de todo su rreyno, y para echar el sello a todo es muy verdadero y es muy crystyanysymo, temeroso de Dyos y muy justo y amygo de pobres en gran manera. (c 1492, Anónimo: La corónica de Adramón)

91. Et qu jeres orar \& o nrrar 1 os fue gos de 1 os cal deos \& los sant uarios de 1 os ba rbaros fec ho serujente de 1 os turcos que rrazon es est a o que muestra de armas para yr a b atalla $\&$ lidiar es amor de franqueza por que engannas el mesquino mundo sy te tu puedes agora meter a serujr tu que mantoujste rroma $\&$ fust e sennor della \& te temjo ella en oy r sola mente el tu nonbre $\&$ a quien ella vio adozjr los rreyes presos de las seluas $\&$ de las tierras de y rcanja $\&$ de las riberas del rrio jndo de tierra de jndia. et asy te vera agora el turco echado del mundo \& abaxado por tus fados \& quebrantado \& alçaran los turc os los sus coraçones commo locos contra tierra de ytalia $\&$ mesuraran asy \& a rroma. (a 1284, Alfonso X: General Estoria. Quinta parte)

92. Y oyendo Leriano tal respuesta diole tanta priesa que lo puso en la postrimera necesidad; y como ciertos cavalleros sus parientes le viesen en estrecho de muerte, suplicaron al rey mandase echar

19 Se trata de una locución muy frecuente en los textos medievales.

${ }^{20}$ Obsérvense las diferentes construcciones sintácticas en las que entra esta construcción.

21 Se trata del único ejemplo localizado. 
el bastón, que ellos le fiavan para que dél hiziese justicia si claramente se hallase culpado; (1482 - 1492, San Pedro, Diego de: Cárcel de amor)

93. Los dichos señores dixeron que mandavan e mandaron a los fieles que lo vean e echen el cordel e todo lo que saliere del camino, el edifiçio, lo derriben a costa del dicho Men Rodriguez. (1493 - 1497, Anónimo: Libro de Acuerdos del Concejo Madrileño)

94. todos los cau alleros assi Napo litanos como calabreses y otros del realme / folgauan en demasia con la dulçe y mesurada conuersacion y llaneza de 1 rey. pesaua $\mathrm{m}$ ucho desto al gran s enescal: que la presencia y tanta magestad del rey desfazia y echaua por tierra todo su fauor / priuança y cabida. (1499, García de Santa María, Gonzalo: Traducción de la Corónica de Aragón de fray Gauberto Fabrici $)^{22}$

\section{9. llevar}

En el caso de llevar, he de decir q ue, excepto en el caso d e llevar en braços, no he localizado usos figurados anteriores a 1400 : llevar la flor y la rama, llevar camino, llevar al cabo, llevar en los hombros, llevar las manos en la cabeza.

95. non podía andar sinon la leuassen omnes o mugeres en braços, (a 1284, Anónimo: Libro de los fueros de Castiella)

96. Que fortuna que se llama / nunca los parte con orden, / antes con todo desorden / por el mundo los derrama; / que, si miras, en la cama / a unos los da folgando, / e a otro trabajando / lleva la flor y la rama. (1400 - 1500, VV.AA.: Cancionero castellano del s. XV de la Biblioteca Esténse)

97. VENIDO el R ey a Berianga , llevando camino co ntra la v illa e castillo d e Atien ça (c 1453 , Anónimo: Crónica de Don Álvaro de Luna)

98. el segundo, que por el se ñor Prínçipe se $\mathrm{r} \tan \mathrm{m}$ oço, que rreçelaua e 1 fecho c omençado e arriscado, que n o sería c onstante pa ra lo llevar al cabo hasta la de vida exec uçión; ( a 1454 , Carrillo de Huete, Pedro: Crónica del halconero de Juan II)

99. que verdaderamente niego a mí mesma con asaz dificultad, e trabajo tomar la cruz mía, que es el tormento desta co tidiana plaga, en las $\mathrm{m}$ anos del con tentamiento in terior. E llevándola en los onbros de la fl aca humanidad con a saz pena, ¿qué hago otra cosa syno seguir al Saluador non con pasos corporales, mas con los afectos del ánima, corriendo en el olor de los enguentos suyos que son las sus preçiosas llagas, de las quales Él, por su grant caridad, quiso ser vngido e quiere vngir a los que para sý escoje? (p 1450, Cartagena, Teresa de: Admiración Operum Dey) ${ }^{23}$

100."Malas nueva s son esas ," d yxo el conde, "porque enpa chándonos c on ellos en otras partes podrya acaeçer algo que $m$ ucho más dañase, no pudyendo proveer en todo. Que ellos poco $\mathrm{m}$ al nos harán -pues no quieren syno dyneros- poco mal es; no por eso se deve de dexar de rremedyar y proveer, qu e au n eso no lleven syno las manos en la cabeça." El co rreo le d yo las cartas; leydas, dyxo: "Byen será rremedyar y presto." Fuese a paso, esperando a los cavalleros que con él venyan y atrás qu edavan, y a lo s que adelante yvan, enbyó a mandar que esperasen. (c 1492, Anónimo: La corónica de Adramón) $)^{24}$

${ }^{22}$ Echar por tierra es una expresión m uy frecue nte en los te xtos m edievales pe ro siempre con un significado literal. Solo he encontrado 2 ejemplos con uso figurado.

${ }^{23} \mathrm{C}$ ovarrubias reco ge 1 a va riante llevar en hombros ("idea $\mathrm{d}$ e triun fo, en las un iversidades a lo $\mathrm{s}$ catedráticos sus apasionados y devotos').

24 Llevar las manos en la cabeza sería una variante de la locución recogida por Covarrubias Bolver con las manos en la cabeça con el sentido de 'volver descalabrado o maltratado'. 


\subsection{Meter}

está presente en $\mathrm{m}$ uchas locuciones y es frecu ente la variación fraseo lógica: meter $a$ escusañas, meter a saco mano, meter voces, meter en baraias / meter baraias, meter en la muda / meter en muda, meter espanto, meter fuego, meter sed, meter a los miedos / meter miedo, meter amor, meter mientes / mentes, meter la cara, meter manos sobre algo, meter por mano, meter a la parte, meter la mano en el fuego.

101. Cancer es animal marino el qual qua ndo falla abierta la o stia al rayo de sol metele a escusañas vna pedrezuela por que no pueda tornar a çerrar se \& comelas en trañas della. (1490, Palencia, Alfonso de: Universal vocabulario en latín y en romance)

102.et más falleme asy mesmo en la del axerquia á donde fasta oy no se fallará batallas de cristianos aver lleg ado, y allí fueron metydas á saco mano tres aldeas y tomados muchos prisioneros y ganados. (1470, Fernández de Córdoba, Diego: Carta a Alfonso de Aguilar)

103.E sy fuere de diestro \& metiere bozes de muestra que fallara[n] m ucha caça $(1350 \quad-1400$, Anónimo: Tratado de Cetrería)

104. Rixa feminino es contienda dentre muchos que contiene iniuria. assi que rixoso se dize el hoçico del ca n. el o mbre si empre re gañado \& presto a co ntradezir: \& metido en baraias. ( 1490, Palencia, Alfonso de: Universal vocabulario en latín y en romance)

105. En esta mansion faras / ymagenes pora dannar las miesses \& pora /fazer mal alos que andan en camino. \& a t od / om ne que qui sieres fazer mal. \& po r meter uaraia / \& en emiztad entre los companneros. (1256, Alfonso X: Picatrix)

106. Asy Al gunos dias v no e $\mathrm{n}$ p os ot ro / o de t erçer en t erçer di a ca co $\mathrm{n}$ esto / sel es t ernan 1 as pennolas \& non / seles caera ning una E qua ndo las quisyeren / meter en la muda con(n)uiene / que las trayan en A nte en las manos / veynte dias Aturada miente vno en / pos ot ro E des pues saquen las A / caça E fagan caçar A las que suelen / caçar la caça del Agua por tal / que se mojen quando la pris yeren $\mathrm{Ca} /$ esta es vna de la s cosas que les / faze mas A yna echar las pennolas (1350 - 1400, Anónimo: Tratado de Cetrería)

107. otrosy conuje ne que fagan / A la s Aues menores caçadores delas / non meter en muda fasta quelas / trayan en las manos Asy commo Auemos / dicho delas Aues mayores ( 1350 - 1400, Anónimo: Tratado de Cetrería)

108. Terreo. res. rui. terrere. es meter espanto: engañar adesora poner grima en balde. Terretur quien se espanta: \& aterresçe: con temor subito. (1490, Palencia, Alfonso de: Universal vocabulario en latín y en romance)

109. Sobreuinientes los gots, metieron fuego en la casa aquella et murio el emperador (1377 - 1399, Fernández de Heredia, Juan: Traducción de Breviarium ab urbe condita, de Eutropio)

110. Onde el mundo tal es commo el agua salada, que quanto más el omne beve della tanto más sed mete. (1251, Anónimo, Calila e Dimna)

111.Et el omne entendido non se deve meter a los miedos fallando otra carrera para [andar] (1251, Anónimo, Calila e Dimna)

112.Et seam os to dos de un con sejo, que le metamos miedo et que le s oltemos el sueño a nuestra guisa; et el miedo le fará fazer quanto nós quisiéremos et dixéremos. (1251, Anónimo, Calila e Dimna)

113.\& rogar loas porel su nombre que meta amor en coraçon dequal mugier quisieres que ame (1256, Alfonso X: Picatrix)

114.no a de andar mas de a una casa en s o derecho. o en sos quino como qui cata a todas partes en derredor dessi metiendo mientes en 1 o que ha de fazer. (1283, Alfonso X: Libro de ajedrez, dados y tablas) 
115.Et desí pusiéronme con los maestros, et yo non çeçé de continuar en aprender la gramática et de meter la mi cara a sotileza et a buen entendimiento, atanto que vençí a mis conpañeros et a mis iguales, et valí más que ellos. (1251, Anónimo, Calila e Dimna)

116. Si p or aue ntura el re ptado fuere ue nzido por cal onia de [que] palacio a s u derecho, el júdez téngalo preso fasta que pa gue, si non die re lueg o e n el canp o fi anças ual ederas p or toda la demanda. Mas palacio nunca meta manos sobr'él, como el fuero manda. Estas son las armas del cauallero, segunt del fuero: loriga, brahoneras de fierro, yelmo, escudo et lança et dos espadas. (c 1300, Anónimo, Fuero de Teruel)

117. Díssoli el judío: "Y o bi en los tomaré, / y o ot ros fiadores n on te demandaré; / mas si tú me fallieres, a ello s reptaré, / e cu ál lealtad traes sab iente la faré." / Dio li los fiado res al tru fán el christiano, / a Madre e a Fijo metiógelos por mano; / pusieron de su paga su término certano, / recivió la pec unia el bu rgés ci bdadano. (1246 - 1252, Berceo, Gonzalo de: Los Milagros de Nuestra Señora)

118.las otras simjentes se esfuerçan a meter a la parte de suso. es a saber en las fojas. (1380 - 1385, Ferrer Sayol, Libro de Palladio)

119. Et para las guardar amas, ha mester muy buenas obras et muy grant entendimiento, que tan grand cosa es de fazer esto c ommo meter la mano en el fuego et non sentir la su calentura. (1325 1335, Manuel, Juan: El Conde Lucanor) ${ }^{25}$

\subsection{1. sacar}

De nuevo, encontramos con el verbo sacar expresiones relativamente tardías; solo sacar algo de mano de alguien se documenta antes del siglo XV: sacar de cordura, sacar de pila, sacar de trabajo y peligro, sacar de entre las manos.

120. Allí vere des destreza / andar con bue na uentura, / donde gracia et nobleza / me sacaron de cordura. (c 1407 - 1463, Mosén Rebellas: Sin título [Cancionero de Estúñiga])

121.ca padre espritual eres de vn su hijo \& tu le sacaste de pila quan do fue xpistiano (1402, López de Ayala, Pero: Caída príncipes)

122. A 1 os quales la di vina cl emençia saco de trabajo e peligro yn conportable. $(1481$ - 1482 , Anónimo: Crónica de Enrique IV de Castilla)

123. Oviera Menalao buen derecho tomado, / que lo oviera muerto o l'oviera llevado; / mas acorrióle otro, sacógelo de mano, / tornáronlo a Troya maltrecho e lazrado. (1240 - 1250, Anónimo: Libro de Alexandre)

124.SEMPRONIO. Madre, ningún provecho trae la memoria del buen tiempo si cobrar no se puede, antes tristeza. Como a ti agora, que nos has sacado el placer de entre las manos. Álcese la mesa; irnos hemos a hol gar, y tú darás respuesta a esta doncella que aquí es venida. (c 1499 - 1502, Rojas, Fernando de: La Celestina. Tragicomedia de Calisto y Melibea)

\subsection{2. volver}

En el caso de volver hay también muchos casos de vari ación fraseológi ca. De nuevo, solo he documentado un ejemplo anterior al siglo XV (volver la cabeza): volver los ojos

\footnotetext{
${ }^{25}$ Esta expresión, con el valor de 'jurar con seguridad', se ha conservado en español con el verbo poner.
} 
atrás / volver atrás los ojos / volver los ojos, volver la hoja, volver(se) los colores, volver cara / volver la cara, volver el rostro, volver espaldas / volver las espaldas, volver las riendas, volver el bulto, volver palabras, volver ruido.

125.e dize aquesta copla que ya no se menbrava de aquesta ley e por eso quería volver los ojos atrás, e esta menbrança non es sal vo de las penas del infierno que, en quanto omne pi ensa en el las, abstiénese del pecado e, quando omne non considera estas cosas, vuelve atrás los ojos, conviene a saber al p ecado en que an tes era. (c 1439, Mena, Juan de: Comentario a la "Co ronación del Marqués de Santillana")

126.e aquest o acaesçe a los om nes por diabólica subj eçión, e después que son salidos del pecado mortal e están en verdadera penitençia, querrían los ojos volver, conviene a saber a los pecados que dexaron atrás de que avían escapado. (c 1439, Mena, Juan de: Comentario a la "Coronación del Marqués de Santillana")

127. CALISTO. Bien lo conoz co, pero no tengo sof rimiento $\mathrm{p}$ ara $\mathrm{m}$ e abstener de adora $\mathrm{r}$ tan alta empresa. CELESTINA. ¿Empresa? Aquélla es empresa que de grado es dada, pero ya sabes que lo hizo por amor de Dios, para guarecer tus muelas, no por el tuyo, para c errar tus llagas. Pero si yo vivo, ella volverá la hoja. (c 1499 - 1502, Rojas, Fernando de: La Celestina. Tragicomedia de Calisto y Melibea)

128.Dixo: "Fijo, non temas, Ni tomes cuidado; / Que alla donde te llevan, Tu seras bien onrado. / Los sueños se a firmaran Que tu as so ñado." / Lueg o se le volvian Sus colores a Y osef. (c 1 400, Anónimo: Poema de Yosef)

129.E fue vençido el dicho Ínigo Lópes porque le falleçieron muchos de los suyos; e con todo, él se recogió con su esta ndarte c on los que quedaron c on él, comm o esforçado ca vallero, a un recuesto, nunca volviendo cara, açerca donde avía seido la batalla e no lo osaron más acometer e tornáronse Aragón. (1471 - 1476, García de Salazar, Lope: Istoria de las bienandanzas e fortunas)

130. Y como dicen, "Mala señal es de am or huir y volver la cara"; sentía en mí gran desfucia desto. (c 1499 - 1502, Rojas, Fernando de: La Celestina. Tragicomedia de Calisto y Melibea)

131.E semejante digo de la oraçion que sy un omne fuesse cruo e duro en dar limosna, e veyendo el pobre volviesse el rostro c ontra la d octrina de Sal amon que dize: "n on buelvas tu cara del pobre". (a 1456, Cartagena, Alfonso de: El Oracional)

132. E como los christianos se veían así perescer, començaron de volver sobre sí, empero no todos. $\mathrm{E}$ aquellos que volvían morían todos luego. E co mo esto veían que los unos no avían caído, los otros buelven espaldas, e quien m ejor podía fuir íva se; e los $\mathrm{m}$ oros e 1 os otros enemigos les davan de es paldas. (c 1430, Corral, Pedro de: Crónica del rey don Rodrigo, postrimero rey de los godos)

133.comenzaron todos de volver las espaldas, e po nerse en fuyda. (c 145 3, Anónimo: Crónica de Don Álvaro de Luna)

134. sintió que estava otro omne en pos dél et volvió la cabeça et vio un omne cabo dél (1325 - 1335, Manuel, Juan: El Conde Lucanor) ${ }^{26}$

135.viendo el en gaño de los p rimeros, volvían las riendas que pa rescía querían pelea r; pero... (c 1492, Maldonado, Alonso: Hechos del Maestre de Alcántara don Alonso de Monroy)

136. Nunca el bulto volvió; nunca la cara rehuyó, ni vencida por gemido lágrimas echó. Fi nalmente, desque ella v enció todas las maneras de penas, el cu chillo que bu scaba halló. (1468, Córdoba, Fray Martín de: Jardín de nobles doncellas)

137. E la causa d'esta muerte fue que, estando todos en buena paz, jugavan a los huevos, como era Pascua, Sanc ho de S omeano e Sanch o D uru e volvieron palabras en 1 a taverna de la Canpa anbos sobre una blanca de huevos e corrieron los de Villa a estos de Garaiçával fasta so las casas de Someano e Sancho Duru e Pero de Castillo por la espald a de una lança; e t ornó Sancho de Someano sobre él e diole con un dardo por los pechos e con una lança por la voca e cay ó luego muerto. (1471 - 1476, García de Salazar, Lope: Istoria de las bienandanzas e fortunas)

\footnotetext{
${ }^{26}$ Covarrubias recoge la variante bolver cabeça con el sentido de 'favorecer'.
} 
138.E por fazer e nojo a los christianos fizo ensuziar el sepulc ro del mártil Sant Venito faziendo dar de comer a sus cavallos sobre el su altar. E puso sus omes con ellos e volvióseles roído con los de la villa e fueron vençidos él e los suyos e muertos muchos d'ellos e co rridos de allí. (147 1 1476, García de Salazar, Lope: Istoria de las bienandanzas e fortunas)

\subsection{3. entrar}

En el caso de entrar todos los ejemplos son del siglo XV: entrar de golpe, entrar de rondón, entrar por la manga y salir por el cabezón.

139. avían de abrir; e avriérongela luego e entraron de golpe todos en ella con grande bolliçio. (1471 - 1476, García de Salazar, Lope: Istoria de las bienandanzas e fortunas)

140. No curamos más de ver, / sino entrarnos de rondón / adond e sonava el so $\mathrm{n} / \mathrm{d}$ e aquel cantar y tañer. (1481 - 1496, Encina, Juan del: Poesías [Cancionero])

141.Ca si vos plaze razón, / de lo tal serés c ontentos. / ¡Quánto nuzen los aumentos / tomados por opinión! / Refrénevos discreçión, / apartadvos de tal fanga, / ca si entra por la manga / sale por el cabeçón. (1453, Marqués de Santillana: Doctrinal de privados)

\section{Reflexiones finales}

Nuestro caudal léxico se ha visto enri quecido históricam ente con una serie de expresiones figuradas compartidas por la comunidad. Puede observarse, a la vista de los ejemplos mostrados, que, aunque muchas de estas locuciones han desaparecido, hay otras que han mantenido su vitalidad en español a lo largo de los siglos ( abrir los ojos, cerrar la puerta, andar de puerta en puerta, caer en la red, entrar de rondón, volver las espaldas, echar mano...). Conocer su recorrido a través d e las distin tas épocas $n$ os permite conocer un poco $\mathrm{m}$ ás a fondo nuestra lengua actual y los $\mathrm{m}$ ecanismos de creación léxica con los que contamos.

Entre las expresiones que han sobrevivi do quiero llam ar la atención sobre el hecho de que muchas de ellas hacen referencia a las partes del cuerpo, ya que rem iten a realidades que siguen estando vigentes para el hablante. ${ }^{27}$

\footnotetext{
${ }^{27}$ Xavier Pascual presenta un proy ecto de tesis para est udiar las unidades fraseológicas de b ase latina y cita algunas co mo volver las espaldas. En este sentido, señala có mo las locuciones con par tes del cu erpo son básicamente las que h emos h eredado d el latín. Por ot ra parte, uno de los prim eros trabajos ded icados a 1 estudio de la fraseología en español antiguo es el de la tesis de Mar Forment (1999) que versa, precisamente,
} 
Por otra parte, frecuentem ente, obs ervamos expresiones cuyo significado nos resulta opaco porque se refieren a rea lidades ya desconocidas para nosotros ( echar el bastón, echar el cordel, meter a escusañas...); en esos casos es frecuente que hayan sido sustituidas por expresiones $m$ ás reconocibles. También el cambio en la realidad puede provocar algunos casos de variaciones fo rmales; así, por ejemplo, antes se podía meter la mano en el fuego por alguien pero hoy la $\mathrm{m}$ ano no se mete sino que se pone, pues difícilmente podríamos hoy abrir una encim era vitrocerámica o una cocina de gas para meter la mano.

Respecto a los cam bios for males, M ónica Velando (2004), al estudiar la construcción entre dientes hace re ferencia ya a la varia bilidad de la construc ción sintáctica (entre dientes / entre los dientes), que antes veíamos, por ejem plo, en venir a mano / a la mano /a las manos, y a la variación sinonímica (entre (los) labios, entre los paladares) que se observa también entre volver la cara / volver el rostro, lo que no hace más que reforzar la idea de que, aunque habl amos de fórmulas fijadas, no existe una fijación absoluta a lo largo de nuestra historia lingüística.

Precisamente, si hablamos de f ijación formal, tenemos que recordar la multitud de cambios que hemos encontrado en las fórm ulas analizadas: unas veces hablam os de diferencias en el núm ero (abrir el ojo / abrir los ojos); otras del uso de un régimen distinto (echar mano a / echar mano de); otras, de la posibilidad de usar distintos verbos (ir / pasar a vela tendida o remo) y otras, com o aca bo de señalar, incluso, de variaciones sinonímicas (volver el bulto / volver la cabeza). Téngase en cuenta que, al tratarse de locucion es con una $b$ ase verb al, e stán su jetas tam bién o bviamente a la variación m orfológica habitual del verbo. ${ }^{28}$ Quitando este ú ltimo tipo d e cam bio, es difícil dar una explicación al hecho de que en algunas fórm ulas se dé la posibilidad de variación y en otras no; sobre este punto y sobre el m omento en que cesa la posibilidad de variación ya reflexionaba Echenique (2003: 531-532): “Cuando la fijación es un

sobre las un idades fraseo lógicas con partes del cuerpo. Para la utili zación de ojo en la fraseología, vé ase Nissen (2006).

${ }^{28}$ Sobre el concepto de fijación tanto formal como pragmática profundiza Montoro del Arco (2006: 3848). Este mis mo autor presenta un apartado muy interesante sobre la variabilidad de las UFs (200 6: 4966). Véase también Serradilla (2006: 77-82) para el estudio de la variación fraseológica. 
hecho inamovible, ¿quiere decir que se ha cer rado el proceso histór ico de variación sin que haya ya ningún $m$ argen de variab ilidad com o consecuencia del bloq ueo producido?”. Hoy por hoy, no tenem os datos, com o decí a al principio, para saber cuándo nace o $\mathrm{m}$ uere una expresión, cuándo adquiere o pierde un valor $\mathrm{m}$ etafórico interpretable com o tal por los habla ntes; pero tam poco contam os con 1 os datos para saber en qué $\mathrm{m}$ omento se fija definitivam ente $\mathrm{y}$, de hecho, no creo que tam poco podamos te ner la certeza de que se ha pr oducido una fijación que no adm ita cambios futuros. La repetición está en la base de la fijación, com o ya señalaba Zuluaga (1992), pero la repetición puede sopor tar cierto $m$ argen de variabilidad, que no sabem os hasta dónde puede llegar.

He hecho referencia, asimismo, en el trabajo al concepto de desautomatización o manipulación voluntaria de una unidad fraseológica para conseguir determ inados efectos de tipo pragmático. Estamos ante un tipo de variación diferente a la que venimos viendo aquí, ya que en este caso se trata de una modificación voluntaria por parte del hablante; este hecho se da básicamente en la oralidad y, aunque hay docum entación abundante en textos contem poráneos, es realm ente difícil rastrear su presencia en los textos antiguos.

He intentado, en fin, presentar un panoram a míni mo de las unidades fraseológicas en españ ol m edieval consti tuidas por una serie de verbos, los de movimiento, que presentan una gran capacidad para extenderse $m$ etafóricamente y adquirir un significado figurado. Se trata de unidades en las que hay un distinto grado desplazamiento semántico: así, he presentado ejemplos en los que el verbo m antiene su valor pero la com plementación proporciona el carácter figura do a la expresión ( entrar de rondón), he proporcionado también casos en los que ya se percibe la m etaforización del verbo pero sigue siendo deducible su valor por las unidades que com ponen la expresión (caer en olvido) y, por último, he incluido ejemplos en los que la expresión es prácticamente opaca ( ir por lana y venir sin pluma). He m ostrado sus usos y he mencionado algunas de sus características se mánticas, morfológicas y sintácticas; así como sus posibilidades de variación. Queda mucho por hacer pero, como señalaba al principio de este trab ajo, estudios de estas características empiezan a abrir puertas y espero que pronto podamos tener un conocim iento más profundo de la evolución de la fraseología española a lo largo de la historia. 
Apéndice

Se recogen, a continuación, los significa dos de aquellas frases analizadas cuyo significado hoy resulta opaco: ${ }^{29}$ abrir tienda 'salir en público con su trato; suélese tomar en mala parte, hablando de las mujeres libres', cerrar las orejas 'no admitir razón', caer en el lazo/ caer en mal lazo 'estar en el trabajo que su enemigo le deseaba tener para su venganza', ir a mesa puesta 'irse a com er adonde no ha hecho ningún servicio ni merecido la com ida; esto hacen muchos por ahorrar su puchero', ${ }^{30}$ ir a la mano 'estorvarle, contradezirle', 'reportarse', írsele por pies 'huir', venir en rostro "ser fría la temperatura, refrescar", ${ }^{31}$ venir a la mano 'es de caçadores de bolatería' , venir algo/alguien a las manos 'empezar a reñir', venir con mano armada 'es con gente, para pelear o reñir', andar a monte 'andar forajido', andar a casa y a monte "andar forajido", andar a grillos "ocuparse en cosas i nútiles o baladíes" ( DRAE), andar a rabo de borrega "andar a rastras, perezosamente", andar a toma el cuerno "ponerse los cuernos uno a otro", ${ }^{32}$ andar a vara "Dícese de la caballería que va entre las varas de un carruaje" (Dic. Aut.), andar de boda en boda "irse de fiesta en fiesta, de un convite a otro', echar a las espaldas 'olvidar', echar de seso (véase salir de seso), echar cantos 'estar loco', echar suertes 'sortear alguna cosa', echar mano a algo/alguien 'es asirle o prenderle', echar mano de algo/alguien 'es e scogerle', echar mano 'desenvainar la espada', echar el sello 'en un negocio, concluirlo, porque el sello es la postrera cosa que se pone en los instrum entos públicos autenticados, como en bulas, privilegios, ejecutorias, etc.', echar del mundo 'perseguirle', echar el bastón 'entrar de por medio y poner paz entre los am igos que se van encolerizando', echar el cordel 'guardar justicia y sea con tra quien s e fuere', llevar la flor y la rama "llevar, of recer la tota lidad ¿?", meter a escusañas "meter a escond idas", meter a saco mano (Covarrubias recoge la variante sinónim a dar sacomano 'robar'), meter en baraias -meter baraias 'reñir y tener pendencia', meter mientes / mentes: mientes 'vocablo castellano antiguo que vale advertimiento, como parar mientes, ${ }^{33}$ meter la cara "fijarse, prestar atención", meter a la parte 'en algún contrato o juego, entrar con su parte', sacar de pila 'ser su padrino en el bautismo', sacar de trabajo 'sacarle de necesidad', sacar algo de mano de alguien, salir de seso 'enloquecer', salir a plaza (Covarrubias recoge la expresión sacar a plaza con el $\mathrm{m}$ ismo significado de 'publicar') , entrar de rondón 'cuando no se apercibe,

\footnotetext{
${ }^{29}$ Para la mayoría de 1 as definiciones se si gue a C ovarrubias (1611); en l os casos en q ue este aut or no recoge la expresión mencionada, la definición es mía o está extraída de otra fuente y aparece con dobles comillas ("“").

${ }^{30}$ Covarrubias recoge la variante venir a mesa puesta.

${ }^{31}$ Recuérdese el refrán existente desde antiguo: Agosto, frío en rostro.

${ }^{32}$ Este significado lo aporta Julio Rodríguez Puértolas en su edición Poesía crítica y satírica del siglo XV, Madrid: Castalia, 1989.

${ }^{33}$ Efectivamente, en español antiguo son frecuentes expresiones como meter/tener/parar/venir en mientes con el significado de 'prestar atención', 'fijarse en algo'.
} 
admitiendo [ ¿advirtiendo?] primero, o llamando a la puerta', entrar por la manga y salir por el cabezón 'dícese del que habiendo tenido alguna cabida con persona poderosa o señor, se ha ido poco a poco apoderando de él, de $m$ anera que se alza con todo, queriendo $\mathrm{m}$ andar tanto y a veces $\mathrm{m}$ ás que él' , volver la hoja 'mudar de parecer', volver(se) los colores 'demudarse', volver (la) cara "No me volvió cara:"No me favoreció ni aun con mirarm e",, volver (las) espaldas "vale desam pararar', volver la cabeza 'Favorecer a alguno, y en contrario es m ás usado: No me bolvió cabeça, no me favoreció ni aun con mirarm e', volver el bulto "mirar hacia atrás" , volver palabras "discutir", volver ruido "entablar una lucha, pelear".

Recibido: 30 enero 2011

Aceptado: 7 marzo 2011/ Revisado: 9 marzo 2011

Publicado: 19 marzo 2011/ Actualizado (no. doi) 13 mayo 2011

Bibliografía

Acero Durántez, I. (2004): “E 1 tratamiento de la f raseología españo la e italiana en un diccionario bilingüe de 1 siglo XVII", D. Corb ella et al. (eds.), Nuevas aportaciones a la historiografía lingüística, vol. 1, pp. 199-210.

Álvarez de la Granja, María (ed.) (2008): Lenguaje figurado y motivación, Frankfurt am Main: Peter Lang.

Ángelova Nénkova, Véselka (2008) “La com paración, la m etáfora y la m etonimia: recursos principales para la creació n de unidades fraseológicas”, en Álvarez de la Granja (ed.), pp. 19-28.

Bibliografía sobre fraseología: http:/www.ub.edu/crai/fil o/bib.php?text=fraseolog\% EDa\&camp $=$ clau\&ordre $=$ autor\&sentit $=$ ASC

Bosque, Ignacio (2004) (dir.): $\quad$ REDES. Diccionario combinatorio del español contemporáneo, Madrid: SM.

Corpas Pastor, Gloria (1997): Manual de fraseología española, Madrid: Gredos.

Corpas Pastor, Gloria (2003a): Diez años de investigación en fraseología: análisis sintáctico-semánticos, contrastivos y dialectológicos, Madrid: Iberoam ericana Vervuert, 
Corpas Pastor, Gloria (ed.) (2003b): Las lenguas de Europa: estudios de fraseología, fraseografía y traducción, Granada: Comares.

Covarrubias, Sebastián de (1611): Tesoro de la lengua castellana o española, ed. de Felipe C.R. Maldonado, revisada por Manuel Camarero, Madrid: Castalia, 1995.

De Miguel, Elena, Azucena Palaci os y Ana Serradilla (eds.) (2006): Estructuras léxicas y estructuras del léxico, Frankfurt am Main: Peter Lang.

De Miguel, Elena, Santiago U. Sánchez Jim énez, Ana Serradilla, Rom ana Radulescu y Olga Batiukova (eds.) (2009): Fronteras de un diccionario: las palabras en movimiento, San Millán de la Cogolla: Cilengua.

Echenique, $\mathrm{M}^{\mathrm{a}}$ Teresa y $\mathrm{M}^{\mathrm{a}}$ José $\quad$ Martínez Alcalde (2003, $2^{\mathrm{a}}$ ed.): Diacronía y gramática histórica, Valencia, Tirant Lo Blanch.

Echenique, Ma Teresa (2003): "Pautas para el estudio histórico de las unidades fraseológicas del español", Homenaje al profesor J. J. Bustos Tovar, Madrid: Universidad Complutense, pp. 545-560.

Forment, Mar (1999): Fijación y uso de algunas unidades fraseológicas del español, Universidad de Barcelona, Tesis Doct oral http://www.te sisenxarxa.net/ TESIS_UB/AVAILABLE/TDX-0515108-124305/02.MMFF_pdf

Forment, Mar (2000): «“Universales m etafóricos” en la significación de algunas unidades fraseológicas», Revista de Lingüística Española, 30, 2, pp. 357-381.

García Page, Mario (2008): $\quad$ Introducción a la fraseología española, Barcelona: Anthropos.

Gómez Molina, José Ramón (2004): “Las unidades léxicas del español”, La enseñanza del léxico en español como segunda lengua / lengua extranjera, Carabela 56, Madrid, SGEL, pp. 27-50.

Koike, Kazumi (2001): Colocaciones léxicas en el español actual: estudio formal y léxico-semántico, Madrid: Universidad de Alcalá / Takushoku University.

Lakoff, George y Mark Johnson (2001, $5^{\mathrm{a}}$ ed.): Metáforas de la vida cotidiana, Madrid: Cátedra. 
Martínez Alcalde, Ma José (2002): "L as unidades fraseológicas en el Diccionario de Terreros”, Boletín de la Sociedad Española de Historiografía Lingüística, 3, pp. 129-149.

Martínez Egido, J. J. y Ruiz Gurillo, L. (2006) : “Las unidades fraseológicas en el inicio de la lexicografía española (1495-1 620)”, J. L. Girón et al. (eds.), Actas del VI Congreso Internacional de Historia de la Lengua Española, vol. 2, pp. 15311544 .

Martínez Montoro, Jorge (2001): "La fraseo logía en los diccionarios del español anteriores al siglo XX”, M. A. Esparza et al. (eds.), Estudios de historiografía lingüística, vol. 2, pp. 905-923.

Montoro del Arco, Estebán Tom ás (2006): Teoría fraseológica de las locuciones particulares, Frankfurt: Peter Lang.

Nissen, Uwe Kjaer (2006): «`¡O jo!’ Un análisis contrastivo de m etáforas y metonimias relativas al 'ojo' en español y en ing lés», en De Miguel, E lena, Ana Serradilla y Azucena Palacios (eds.), pp. 95-110.

Ortega Ojeda, Gonzalo y Mª I. González Agui ar (2005): "En torno a la variación de las unidades fraseológicas”, en Al mela, R., E. Ra món Trives y G. W otjak (eds.), Fraseología contrastiva (con ejemplos tomados del alemán, español, francés e italiano), Murcia: Universidad de Murcia, Universität Leipzig, pp. 91-109.

Pamies, Antonio, W enceslao C. Lozano y B eatriz Cortina (2008): "Las m etáforas del alcohol: contraste translingüístico e intercu ltural”, en Álvarez de la Granja (ed.), pp. 273-286.

Pascual Lóp ez, Xavier: Mem oria del trabaj o "Fraseología de origen latino y m otivo grecorromano", en http://www.recer cat.net/bitstream/2072/6760/1/memoria _xpascual_informe_cast.pdf. [Bibliografía sobre fraseología]

Radulescu, Romana (2005): “Construcciones idiomáticas con el verbo salir en español, inglés y rumano", Verba Hispánica, XIII, pp. 99-111.

Ramos, Alicia y Ana Serradilla (2000): Diccionario Akal del español coloquial. 1492 expresiones del español actual y más..., Madrid: Akal. 
Real Academia Española: Banco de datos (CORDE) [en línea]. Corpus diacrónico del español. $<$ http://www.rae.es> [Fecha de la consulta: junio-julio de 2010]

Real Academia Española: Banco de datos (CREA) [en línea]. Corpus de referencia del español actual. <http://www.rae.es> [Fecha de la consulta: junio-julio de 2010]

Robles y Sabater, Ferrán (2007): "Fuentes para el estudio del tratam iento de la fraseología en la lexicografía española m onolingüe y bilingüe”, Linred. [http://www.linred.es/informacion_pdf/informacion15_04072007.pdf].

Seco, Manuel y Olim pia Andrés (2004): Diccionario fraseológico documentado del español actual, Aguilar, Madrid.

Serradilla C astaño, Ana (2001): "L a enseña nza de frases hechas: un $\mathrm{m}$ étodo para integrar la cultu ra en el aula ", ¿Qué español enseñar? Norma y variación lingüísticas en la enseñanza de español a extranjeros. Actas del XI Congreso Internacional de ASELE, vol. I, Zaragoza: Universidad, pp. 657- 664

Serradilla Castaño, Ana (2004): “ Ir y caer como constituy entes de locuciones fraseológicas que no implican movimiento”, Verba Hispánica, XII, pp. 131-141.

Serradilla Castaño, Ana (2006): "Expresiones idiomáticas con verbos de movimiento en la historia del español: desd e el s iglo XVII has ta la actualidad”, en De Miguel, Elena, Ana Serradilla y Azucena Palacios (eds.), pp. 73-93.

Serradilla Castaño, Ana (2010): “ Abrir, cerrar, subir y bajar: la productividad de los verbos de movimiento como elementos constitutivos de locuciones idiomáticas en español”, Lingüística, L, pp. 81-100.

Serradilla Castaño, Ana (en prensa): "Unidades fraseológicas con verbos de movimiento en español medieval" Actas del XXVI Congreso Internacional de Lingüística y Filología Románicas.

Tristá Pérez, Antonia Ma (1985): "Fuentes de las unidades fraseológicas. Sus m odos de formación” en Carnead o Moré, Zo ila y A. M. Tris tá Pérez (eds. ): Estudios de fraseología, La Habana: Academia de Ciencias de Cuba, pp. 69-90. 
Velando Casanova, M. (2003): "Sobr e las expresiones del tipo non vale un figo en lexicografia", Res Diachronicae: Anuario de la AJIHLE, 2, pp. 405-413 [Edición en línea: http://home.pages.at/resdi /Numeros/Numero2 /Parte1_Art44.pdf]

Velando Casanova, M. (2004): “ Entre dientes: fijación de una unidad fraseológica”, http://www.uji.es/bin/publ/edicions/jfi9/fang/6.pdf.

Wotjak, Gerd (1998): Estudios de fraseología y fraseografía del español, Frankfurt: Vervuert.

Zuluaga, Alberto (1992 ): "Spanisch: Phraseologie”, en Holtu s, G., M. Metzeltin y Ch. Schmitt, ( Hrsg.): Lexicon der Romanistischen Linguistik, Tübingen: Max Niemeyer, Verlag, pp. 125-131. 